\title{
Association between legume intake and self-reported diabetes among adult men and women in India
}

\author{
Sutapa Agrawal ${ }^{* *}$ and Shah Ebrahim ${ }^{1,2}$
}

\begin{abstract}
Background: It is postulated that a diet high in legumes may be beneficial in preventing diabetes. However, little empirical evidence on this association exists in developing countries. We aimed to examine the association between legume intake and self-reported diabetes status in adult men and women in India.

Methods: The analysis is based on a population-based cross sectional study of 99,574 women and 56,742 men aged 20-49 years included in India's third National Family Health Survey conducted in 2005-06. Association of legume intake, determined by the frequency of consumption of pulses and beans (daily, weekly and occasionally or never), with the reported prevalence of diabetes were estimated using multiple logistic regression after adjusting for frequency of consumption of other food items, BMI status, tobacco smoking, alcohol drinking, watching television, age, education, living standard of the household, residence and geographic regions.

Results: Daily (OR: 0.71; 95\% Cl: 0.59-0.87; $\mathrm{p}=0.001$ ) and weekly (OR: 0.66; 95\% Cl: 0.54-0.80; $p<0.001$ ) legumes intake were associated with a significantly reduced prevalence of diabetes among adult Indian women even after controlling for the effects of potentially confounding factors, whereas non-significant inverse associations were observed in men.

Conclusion: Daily or weekly intake of legumes was inversely associated with presence of diabetes in the Indian population. However, this is an observational finding and uncontrolled confounding cannot be excluded as an explanation for the association. More epidemiological research with better measures of legumes intake and clinical measures of diabetes is needed to clarify this relationship.
\end{abstract}

Keywords: Legume intake, Diabetes, Men, Women, NFHS-3, India

\section{Background}

The independent association between legume intake and diabetes risk is not well documented, particularly in developing countries. As the prevalence of type 2 diabetes mellitus has been increasing rapidly worldwide, [1] knowledge of risk factors and protective factors associated with diabetes is essential for the development of prevention strategies. Legumes-including pulses, beans, lentils, peanuts, peas, and soybeans-are good sources of fiber and have a low glycemic index (GI) [2]. It has been postulated that a diet high in legumes may be beneficial in preventing

\footnotetext{
*Correspondence: sutapaiips@rediffmail.com

'South Asia Network for Chronic Disease, Public Health Foundation of India, C1/52, First floor, Safdurjung Development Area, New Delhi, India Full list of author information is available at the end of the article
}

diabetes. Consumption of legumes is recommended by the European [3], Canadian [4] and American Diabetes Associations [5] as a means of increasing one's daily fiber intake and lowering GI for diabetes control. In India, however, diabetes prevalence is increasing in both rural $[6,7]$ and urban [7-10] populations, despite the consumption of traditional diets high in legumes [11].

Epidemiologic studies in the West, where the average daily intake in grams is much lower than in India, have yielded inconsistent associations on legume intake and chronic conditions [2,12-18]. Given the high growing prevalence of diabetes in India, the role of various food items needs to be examined in relation to its prevalence. Legume consumption is ubiquitous in India as more than half the Indian population consumes it daily [19].

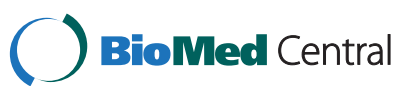


There is a dearth of empirical research in India regarding the role of legumes in the prevention of diabetes. India's third National Family Health Survey (NFHS-3, 2005-06) collected data from 109,041 households on a wide range of dietary, societal, lifestyle, and environmental determinants of morbidity and chronic ailments, including diabetes, for adult men aged 15-54 years and women aged 15-49 years, [19] and covered regions comprising more than $99 \%$ of India's population. These data provide a unique opportunity to study the association between legumes consumption and the prevalence of diabetes. In this paper, we assessed whether daily or weekly intake of legumes was associated with a lower risk of diabetes among adult Indians.

\section{Methods}

Data

Data from NFHS-3, 2005-06 were used for this study. Details of the survey method including sampling frame and questionnaire used are provided in the basic survey report for all India [19]. Briefly, this survey was designed on the lines of the Demographic and Health Surveys (DHS) (available at www.measuredhs.com) that have been conducted in more than 90 developing countries since the 1980s. NFHS has been conducted in India for three successive rounds, each at an interval of five years. NFHS-3 collected demographic, socio-economic, and health information from a nationally representative probability sample of 124,385 women age 15-49 and 74,369 men aged 15-54 residing in 109,041 households. The sample is a multistage cluster sample with an overall response rate of 98 percent. All the states of India are represented in the sample (except the small Union Territories), covering more than 99 percent of the country's population. The analysis in this study is restricted to 99,574 women and 56,742 men aged 20-49 years living in the sample households.

\section{Response variable}

The survey asked several questions relating to the current health status of the respondents, including the question, 'Do you currently have diabetes?' The survey was conducted using an interviewer-administered questionnaire in the native language of the respondent using a local, commonly understood term for diabetes. A total of 18 languages were used in the survey with back translation into English to ensure accuracy and comparability. No physician diagnosis of diabetes could be obtained to verify self reports and it was not possible to take fasting blood glucose to establish a diagnosis. In our analysis, reported prevalence of diabetes is the outcome of interest.

\section{Predictor variables and covariates}

The survey collected information on demographic and socio-economic factors, anthropometric measurements and dietary intake. Consumption of selected foods was assessed by asking, 'How often do you yourself consume the following food items: daily, weekly, occasionally or never?' This question was asked with respect to the following foods - legumes (including pulses or beans), milk or curd, green leafy vegetables, other vegetables, fruits, eggs, chicken, meat or fish. Frequency of watching television (almost every day, at least once weekly, less than once weekly, not at all) was used as a measure of sedentary behaviour. Use of tobacco was measured as never smoker and ever smoker. Use of alcohol was quantified as drinks almost every day, about once weekly, less than once weekly and never. Indian adult population standard [20] categories of Body Mass Index (BMI, $\mathrm{kg} / \mathrm{m}^{2}$ ) were used: $\leq 18.5 \mathrm{~kg} / \mathrm{m}^{2}$ (underweight); 18.5 to $22.9 \mathrm{~kg} / \mathrm{m}^{2}$ (normal), 23.0 to $24.9 \mathrm{~kg} / \mathrm{m}^{2}$ (overweight), and $\geq 25.0 \mathrm{~kg} / \mathrm{m}^{2}$ (obese).

Because the effects of legume intake on the prevalence of diabetes are likely to be confounded with the effects of other factors, it is necessary to statistically control, or adjust for such factors. Control variables were chosen based on earlier evidence, theoretical knowledge, and the availability of the variables in the NFHS-3 data. Earlier studies have associated the prevalence of self-reported chronic conditions with age, sex [25], income, education, religion and rural/urban residence [21-26]. Control variables included in this analysis are: age (20-29, 30-39, 40-49 years); education (illiterate, literate but less than middle school complete, middle school complete but less than high school complete, high school complete or higher); religion (Hindu, Muslim, Christian, Sikh, Other); caste/tribe (scheduled caste, scheduled tribe, other backward class, others, missing caste); wealth status (based on 33 assets and housing characteristics graded lowest, second, middle, fourth, highest) was computed using previously described methods [19]; and place of residence (urban, rural). For a detailed definition of variables see Table 1.

\section{Statistical analysis}

Descriptive statistics were calculated with use of standard methods (such as frequencies and percentages) in men and women separately. Prevalence of diabetes was computed as percentage prevalence. Differences were tested using $X^{2}$ tests. Trend tests were also carried out scoring the variables in different categories by using likelihood ratio tests. Multiple logistic regression models were used to estimate the odds ratios of daily and weekly legume intake on risk of diabetes after controlling for potential confounders and also examining the independent effects of risk factors. The following models were constructed to account for potential confounders and mediators: Model 1 presents unadjusted results; Model 2 presents results adjusted for the consumption of other 
Table 1 Sample distribution and prevalence of diabetes $(\%)$ among men $(n=56,742)$ and women $(n=99,574)$ aged 20-49 years according to legumes intake and other selected risk factors and background characteristics, India 2005-06

\begin{tabular}{|c|c|c|c|c|c|c|}
\hline \multirow[t]{2}{*}{ Characteristics } & \multicolumn{3}{|c|}{ Men } & \multicolumn{3}{|c|}{ Women } \\
\hline & $\begin{array}{c}\text { Total number } \\
\mathrm{N}[\%]\end{array}$ & $\begin{array}{c}\text { Who have diabetes } \\
\mathrm{N}[\%]\end{array}$ & $x^{2} p$ value* & $\begin{array}{c}\text { Total number } \\
\mathrm{N}[\%]\end{array}$ & $\begin{array}{c}\text { Who have diabetes } \\
{[\%]}\end{array}$ & $\mathrm{X}^{2} \mathrm{p}$ value* \\
\hline Legumes intake & & & $<0.0001$ & & & $<0.0001$ \\
\hline Daily & $29863[52.6]$ & $437[1.5]$ & & $52440[52.7]$ & $538[1.0]$ & \\
\hline Weekly & $21705[38.3]$ & $219[1.0]$ & & $36597[36.8]$ & $360[1.0]$ & \\
\hline Occasionally & $4660[8.2]$ & $51[1.1]$ & & $9663[9.7]$ & $131[1.4]$ & \\
\hline Never & $505[0.9]$ & $13[2.6]$ & & $852[0.9]$ & $20[2.3]$ & \\
\hline
\end{tabular}

Consumption of

other food items

Milk or curd

$<0.0001$

$<0.0001$

Daily
Weekly
Occasionally
Never

26307[46.4]

$391[1.5]$

$11554[20.4]$

117[1.0]

$14757[26.0]$

$138[0.9]$

Never

$4114[7.3]$

$74[1.8]$

Green leafy vegetables

Daily

Weekly

Occasionally/never

Fruits

$$
\text { Daily }
$$

Weekly

Occasionally

Never

Eggs

Daily

Weekly

Occasionally

Never

Fish intake

Daily
Weekly
Occasionally
Never

Chicken or meat

Daily
Weekly
Occasionally
Never

Body mass index and lifestyle factors

Body mass index $\left(\mathrm{kg} / \mathrm{m}^{2}\right)^{a}$

$\leq 18.5$ (Underweight)
33982[59.9]

453[1.3]

$231[1.2]$

35[1.0]

7320[12.9]

$125[1.7]$

255[1.3]

296[1.0]

$44[2.8]$

2931[5.2]

56[1.9]

20682[36.5]

$317[1.5]$

201[1.0]

146[1.1]

13330[23.5]

$3706[6.5]$

$90[2.4]$

238[1.7]

225[1.0]

167[1.0]

706[1.2]

6[0.9]

15609[27.5]

269[1.7]

26135[46.1]

291[1.1]

14272[25.2]

155[1.1]

$\begin{array}{ll}40366[40.5] & 492[1.2] \\ 15071[15.1] & 138[0.9] \\ 32918[33.1] & 302[0.9] \\ 11202[11.3] & 117[1.0]\end{array}$

0.149

64095[64.4]

0.090

28606[28.7]

674[1.1]

286[1.0]

6840[6.9]

89[1.3]

$<0.0001$

12789[12.9]

$<0.0001$

26731[26.9]

206[1.6]

276[1.0]

503[0.9]

63[1.7]

$<0.0001$

3631 [3.6]

$<0.0001$

3475[3.5]

$60[1.7]$

28778[28.9]

363[1.3]

32635[32.8]

287[0.9]

$340[1.0]$

$<0.0001$

$<0.0001$

$$
\text { 6505[6.5] }
$$

149[2.3]

22070[22.2]

304[1.4]

34242[34.4]

264[0.8]

36724[36.9]

331 [0.9]

$<0.0001$

839[0.8]

$<0.0001$

21938[22.0]

14[1.7]

292[1.3]

42222[42.0]

423[1.0]

$34537[34.7]$

320[0.9]

$<0.0001$

$<0.0001$ 
Table 1 Sample distribution and prevalence of diabetes $(\%)$ among men $(n=56,742)$ and women $(n=99,574)$ aged 20-49 years according to legumes intake and other selected risk factors and background characteristics, India 2005-06 (Continued)

\begin{tabular}{|c|c|c|c|c|c|c|}
\hline 23.0-24.9 (Overweight) & $5635[10.5]$ & $128[2.3]$ & & $9454[9.9]$ & $153[1.6]$ & \\
\hline$\geq 25.0$ (Obese) & $5881[11.0]$ & $178[3.0]$ & & $14169[14.8]$ & $437[3.1]$ & \\
\hline Current tobacco smoking & & & 0.498 & & & 0.514 \\
\hline No & $35422[62.4]$ & $450[1.3]$ & & 97738[98.2] & $1030[1.1]$ & \\
\hline Yes & $21321[37.6]$ & $270[1.3]$ & & $1835[1.8]$ & $19[1.0]$ & \\
\hline Alcohol consumption & & & 0.362 & & & 0.020 \\
\hline Never & $35965[63.4]$ & $436[1.2]$ & & $97101[97.5]$ & $1037[1.1]$ & \\
\hline Occasionally & $13054[23.0]$ & $180[1.4]$ & & $1067[1.1]$ & $7[0.7]$ & \\
\hline Once a week & $5676[10.0]$ & $74[1.3]$ & & $1010[1.0]$ & $3[0.3]$ & \\
\hline Almost everyday & $2048[3.6]$ & $31[1.5]$ & & $396[0.4]$ & $1[0.3]$ & \\
\hline Frequency of watching TV & & & $<0.0001$ & & & $<0.0001$ \\
\hline Not at all & $10517[18.5]$ & $112[1.1]$ & & $35399[35.6]$ & $255[0.7]$ & \\
\hline Less than once a week & $11420[20.1]$ & $95[0.8]$ & & $10438[10.5]$ & $96[0.9]$ & \\
\hline At least once a week & $9081[16.0]$ & $114[1.3]$ & & 10952[11.0] & $100[0.9]$ & \\
\hline Almost everyday & $25717[45.3]$ & $400[1.6]$ & & $42763[43.0]$ & $598[1.4]$ & \\
\hline \multicolumn{7}{|l|}{ Background factors } \\
\hline Age & & & $<0.0001$ & & & $<0.0001$ \\
\hline $20-29$ & $22842[40.3]$ & $91[0.4]$ & & 43196[43.4] & $113[0.3]$ & \\
\hline $30-39$ & $19045[33.6]$ & $179[0.9]$ & & $33522[33.7]$ & $342[1.0]$ & \\
\hline $40-49$ & $14855[26.2]$ & $450[3.0]$ & & $22856[23.0]$ & $594[2.6]$ & \\
\hline Education $^{\mathrm{b}}$ & & & $<0.0001$ & & & $<0.0001$ \\
\hline Illiterate & $11607[20.5]$ & $144[1.2]$ & & $45113[45.3]$ & $338[0.7]$ & \\
\hline Literate, $<$ middle school & $10030[17.7]$ & $111[1.1]$ & & $14463[14.5]$ & 192[1.3] & \\
\hline Middle school completed & $26783[47.2]$ & $320[1.2]$ & & $31665[31.8]$ & $435[1.4]$ & \\
\hline High school complete and above & $8311[14.7]$ & $146[1.8]$ & & $83284[8.4]$ & $83[1.0]$ & \\
\hline Religion & & & 0.099 & & & $<0.0001$ \\
\hline Hindu & $46727[82.3]$ & $575[1.2]$ & & $80648[81.0]$ & $792[1.0]$ & \\
\hline Muslim & $6841[12.1]$ & $103[1.5]$ & & $12940[13.0]$ & $164[1.3]$ & \\
\hline Christian & $1290[2.3]$ & $19[1.5]$ & & $2526[2.5]$ & $56[2.2]$ & \\
\hline Sikhs & $1009[1.8]$ & $17[1.7]$ & & $1836[1.8]$ & $21[1.1]$ & \\
\hline Others $^{c}$ & $876[1.5]$ & $6[0.7]$ & & $1624[1.6]$ & $16[1.0]$ & \\
\hline Caste/tribe $e^{d}$ & & & $<0.0001$ & & & $<0.0001$ \\
\hline Scheduled caste & $10670[18.8]$ & $131[1.2]$ & & $18260[18.3]$ & $173[0.9]$ & \\
\hline Scheduled tribes & $4732[8.3]$ & $24[0.5]$ & & $8002[8.0]$ & $30[0.4]$ & \\
\hline Other backward class & $22116[39.0]$ & $256[1.2]$ & & $38860[39.0]$ & $368[0.9]$ & \\
\hline Others & $17414[30.7]$ & $270[1.6]$ & & $31440[31.6]$ & $437[1.4]$ & \\
\hline Missing caste & $1810[3.2]$ & $40[2.2]$ & & $3011[3.0]$ & $41[1.4]$ & \\
\hline Wealth index & & & $<0.0001$ & & & $<0.0001$ \\
\hline Lowest & $9103[16.0]$ & $71[0.8]$ & & $17286[17.4]$ & $71[0.4]$ & \\
\hline Second & $10205[18.0]$ & $100[1.0]$ & & $18546[18.6]$ & $141[0.8]$ & \\
\hline Middle & $11533[20.3]$ & $80[0.7]$ & & $19698[19.8]$ & $152[0.8]$ & \\
\hline Fourth & $12634[22.3]$ & $154[1.2]$ & & $20925[21.0]$ & $275[1.3]$ & \\
\hline
\end{tabular}


Table 1 Sample distribution and prevalence of diabetes $(\%)$ among men $(n=56,742)$ and women $(n=99,574)$ aged 20-49 years according to legumes intake and other selected risk factors and background characteristics, India 2005-06 (Continued)

\begin{tabular}{|c|c|c|c|c|c|c|}
\hline Highest & $13266[23.4]$ & $316[2.4]$ & & $23119[23.2]$ & $411[1.8]$ & \\
\hline Place of residence & & & $<0.0001$ & & & $<0.0001$ \\
\hline Urban & $20779[36.6]$ & $347[1.7]$ & & $33355[33.5]$ & $551[1.7]$ & \\
\hline Rural & $35963[63.4]$ & $373[1.0]$ & & $66219[66.5]$ & $498[0.8]$ & \\
\hline Geographic regions $^{\mathrm{f}}$ & & & $<0.0001$ & & & $<0.0001$ \\
\hline North & $7767[13.7]$ & $60[0.8]$ & & $13286[13.3]$ & $116[0.9]$ & \\
\hline Northeast & $2313[4.1]$ & $23[1.0]$ & & $3978[4.0]$ & $28[0.7]$ & \\
\hline Central & $12971[22.9]$ & $82[0.6]$ & & $22250[22.3]$ & $126[0.6]$ & \\
\hline East & $11810[20.8]$ & $213[1.8]$ & & $21913[22.0]$ & $295[1.3]$ & \\
\hline West & $9279[16.4]$ & $90[1.0]$ & & $15052[15.1]$ & $121[0.8]$ & \\
\hline South & $12603[22.2]$ & $252[2.0]$ & & $23096[23.2]$ & $363[1.6]$ & \\
\hline Total percent & & 1.3 & & & 1.1 & \\
\hline Number $^{g}$ & 56742 & 720 & & 99574 & 1050 & \\
\hline
\end{tabular}

an NFHS-3, all respondents were weighed using a solar powered scale with an accuracy of $\pm 100 \mathrm{~g}$. Their height was measured using an adjustable wooden measuring board, specifically designed to provide accurate measurements (to the nearest $0.1 \mathrm{~cm}$ ). Pregnant women and women who had a delivery in the 2 months preceding the survey were excluded from the anthropometric measurements.

${ }^{\mathrm{b}}$ Education: illiterate ( 0 years of education), literate but less than middle school complete (1-5 years of education), middle school complete (6-8 years of education), high school complete or more (9+ years of education).

'Others include Buddhist, Jain, Jewish, and Zoroastrian.

${ }^{\mathrm{d}}$ Scheduled castes and scheduled tribes are identified by the Government of India as socially and economically backward and needing protection from social injustice and exploitation. Other backward class is a diverse collection of intermediate castes that were considered low in the traditional caste hierarchy but are clearly above scheduled castes. Others is thus a default residual group that enjoys higher status in the caste hierarchy.

'The wealth index is based on following assets in the household: household electrification, type of windows, drinking water source, type of toilet facility, type of flooring, material of exterior walls, type of roofing, house ownership, ownership of a bank or post office account, and ownership of a mattress, a pressure cooker, a chair, a cot/bed, a table, an electric fan, a radio/transistor, a black and white television, a colour television, a sewing machine, a mobile telephone, any other telephone, a computer, a refrigerator, a watch or clock, a bicycle, a motorcycle or scooter, an animal-drawn cart, a car, a water pump, a thresher, and a tractor. fRegion: North: Delhi, Haryana, Himachal Pradesh, Jammu and Kashmir, Punjab, Rajasthan, Uttaranchal; Northeast: Assam, Arunachal Pradesh, Manipur, Meghalaya, Mizoram, Nagaland, Sikkim, Tripura; Central: Chhattisgarh, Madhya Pradesh, Uttar Pradesh; East: Bihar, Jharkhand, West Bengal, Orissa; West: Maharashtra, Goa, Gujarat; South: Andhra Pradesh, Karnataka, Kerala, Tamil Nadu.

${ }^{9}$ Number of men and women varies slightly for individual variables depending on the number of missing values.

* $p$-value is the result of a simple Chi-square test for independence. Pearson Chi-square test is used to examine whether association between the dependent variable (self reported diabetes) and predictor variable (such as legume consumption) and other covariates and confounders was statistically significant.

food items and socio- demographic factors which may be confounders; Model 3 presents results adjusted for BMI, lifestyle factors and socio-demographic factors which may be confounders; and Model 4 is adjusted for both confounders and mediators to demonstrate any independent effect of legume intake on diabetes. As certain states and certain categories of respondents were oversampled, in all analyses sample weights were used to restore the representativeness of the sample [19].

As the effects of legume intake on the prevalence of diabetes are likely to vary by sex, due to the large gender differences in nutritional status in India, the susceptibility to disease, and access to treatment and care in a developing country, the analysis was carried out separately for women and men. Results are presented in the form of odds ratios (ORs) with 95 percent confidence intervals $(95 \% \mathrm{CI})$. The estimation of confidence intervals takes into account the design effects due to clustering at the level of the primary sampling unit. Before carrying out the multivariate models, we tested for the possibility of multicolinearity between the variables. In the correlation matrix, all pair wise Pearson correlation coefficients are $<0.5$, suggesting that multicolinearity is not a problem. All the analysis including the logistic regression models were conducted using the SPSS statistical software package, version 19.

\section{Ethical considerations}

The NFHS-3 survey received ethical approval from the International Institute for Population Science's Ethical Review Board. Prior informed consent was obtained from each respondent. The analysis presented in this study is based on secondary analysis of existing survey data with all identifying information removed.

\section{Results}

Characteristics of the study population and prevalence of diabetes

Table 1 shows the characteristics of the study population segregated by men and women, according to their legumes intake, selected risk factors and socio-economic and demographic characteristics, and the corresponding 
Table 2 Effect (odds ratios with $95 \% \mathrm{Cl}$ ) of legume intake and selected factors on the risk of diabetes among men ( $\mathrm{n}=56,742)$, India, 2005-06

\begin{tabular}{|c|c|c|c|c|}
\hline Predictors and confounders & $\begin{array}{c}\text { Model } 1 \text { OR } \\
{[95 \% \mathrm{Cl}]}\end{array}$ & $\begin{array}{c}\text { Model } 2 \text { OR } \\
{[95 \% \mathrm{Cl}]}\end{array}$ & $\begin{array}{c}\text { Model } 3 \text { OR } \\
{[95 \% \mathrm{Cl}]}\end{array}$ & $\begin{array}{c}\text { Model } 4 \text { OR } \\
{[95 \% \mathrm{Cl}]}\end{array}$ \\
\hline \multicolumn{5}{|l|}{ Legumes intake } \\
\hline Daily & $0.57[0.32-0.99]$ & $0.68[0.38-1.22]$ & $0.62[0.35-1.11]$ & $0.70[0.39-1.26]$ \\
\hline Weekly & $0.39[0.22-0.69]$ & $0.56[0.31-1.00]$ & $0.51[0.28-0.91]$ & $0.54[0.30-0.98]$ \\
\hline Occasionally & $0.42[0.23-0.79]$ & $0.54[0.29-1.03]$ & $0.52[0.28-0.99]$ & $0.56[0.30-1.07]$ \\
\hline Never $^{R}$ & 1.00[Reference] & 1.00[Reference] & 1.00[Reference] & 1.00[Reference] \\
\hline
\end{tabular}

Consumption of other food items

Milk or curd

$0.84[0.63-1.12]$

$0.71[0.52-0.98]$

Weekly

Occasionally

Never $^{\mathrm{R}}$

Green leafy vegetables

Daily

Weekly

Never/Occasionally

Fruits

Daily

Weekly

Occasionally

Never $^{R}$

Eggs

Daily

Weekly

Occasionally

Never $^{R}$

Fish

Daily

Weekly

Occasionally

Never $^{R}$

Chicken or meat

Daily

Weekly

Occasionally

Never $^{R}$
0.64[0.48-0.87]

$1.00[$ Reference]

$1.04[0.72-1.49]$

$1.17[0.81-1.69]$

1.00[Reference]

$0.34[0.23-0.51]$

$0.35[0.24-0.51]$

$0.39[0.28-0.56]$

1.00[Reference]

$1.59[1.05-2.39]$

1.34[0.97-1.83]

1.09[0.80-1.49]

1.00[Reference]

$1.52[1.03-2.25]$

1.32[0.94-1.87]

1.11 [0.82-1.50]

1.00[Reference]

0.35[0.14-0.86]

0.93[0.63-1.35]

0.83[0.58-1.19]

1.00[Reference] $p$ value for trend

$<0.0001$

$<0.0001$

0.79[0.60-1.06]

$0.64[0.47-0.88]$

$0.60[0.44-0.81]$

1.00[Reference]

0.002

1.00[0.69-1.43]

1.15[0.79-1.66]

1.00[Reference]

$<0.0001$

$0.35[0.22-0.50]$

$0.38[0.23-0.49]$

0.43[0.28-0.56]

1.00[Reference]

0.017

$1.28[0.84-1.94]$

1.18[0.86-1.62]

1.07[0.79-1.47]

1.00[Reference]

0.109

$1.55[1.04-2.33]$

1.32[0.92-1.89]

1.14[0.81-1.60]

1.00[Reference]

0.568

$0.31[0.12-0.82]$

$0.88[0.65-1.42]$

0.72[0.55-1.15]

1.00[Reference]

$<0.0001$

$\begin{array}{ll}0.93[0.73-1.18] & 0.92[0.72-1.16] \\ 1.00[\text { Reference] } & 1.00[\text { Reference }] \\ 1.67[1.34-2.09] & 1.61[1.29-2.00] \\ 1.84[1.49-2.27] & 1.83[1.49-2.27]\end{array}$

0.93[0.73-1.18]

Body mass index $\left(\mathrm{kg} / \mathrm{m}^{2}\right)$

$\leq 18.5$ (Underweight)

18.5-22.9 (Normal) ${ }^{R}$

23.0-24.9 (Overweight)

$\geq 25.0$ (Obese)

Current tobacco smoking
1.84[1.49-2.27]

$<0.0001$ 
Table 2 Effect (odds ratios with $95 \% \mathrm{Cl}$ ) of legume intake and selected factors on the risk of diabetes among men ( $\mathrm{n}=56,742)$, India, 2005-06 (Continued)

No $^{R}$
Yes
Alcohol consumption
Never $^{R}$
Occasionally
Once a week
Almost everyday
Frequency of watching TV
Not at all
Less than once a week
At least once a week
Almost everyday

$\begin{array}{ll}1.00[\text { Reference }] & 1.00[\text { Reference }] \\ 0.93[0.79-1.10] & 0.92[0.78-1.09]\end{array}$

Background factors

Age

$$
\begin{aligned}
& 20-29^{R} \\
& 30-39
\end{aligned}
$$

40-49

$\begin{array}{ll}1.00[\text { Reference }] & 1.00[\text { Reference }] \\ 1.15[0.95-1.40] & 1.15[0.94-1.39] \\ 0.96[0.73-1.26] & 0.94[0.71-1.23] \\ 0.97[0.66-1.44] & 0.97[0.65-1.44]\end{array}$

Illiterate $^{R}$

1.00[Reference]

Literate, <middle school

0.78[0.60-1.01]

Middle school completed

0.75[0.57-0.94]

High school complete and above

0.72[0.53-0.99]

Religion

$\begin{array}{ll}1.00[\text { Reference }] & 1.00[\text { Reference }] \\ 0.86[0.65-1.14] & 0.90[0.67-1.19] \\ 1.23[0.92-1.63] & 1.24[0.93-1.65] \\ 0.84[0.64-1.10] & 0.92[0.70-1.22]\end{array}$

$<0.0001$

1.00[Reference]

2.12[1.62-2.76]

6.96[5.46-8.87]

$\mathrm{Hindu}^{\mathrm{R}}$

1.00[Reference]

Muslim

1.22[0.94-1.58]

Christian

$0.67[0.41-1.09]$

Sikhs

1.63[0.92-2.89]

Others

$0.51[0.20-1.28]$

Caste/tribe

Scheduled caste ${ }^{R}$

1.00[Reference]

scheduled tribes

0.49[0.29-0.70]

Other backward class

0.71[0.62-0.97]

Others

$0.78[0.62-0.99]$

Missing caste

$1.15[0.84-1.94]$

Wealth index

Lowest $^{R}$

1.00[Reference]

Second

1.36[0.99-1.88]

Middle

0.92[0.64-1.32]

Fourth

$1.74[1.21-2.49]$

Highest

$3.48[2.33-5.19]$

Place of residence

Urban

1.07[0.89-1.29]

Rural $^{R}$

1.00[Reference] 
Table 2 Effect (odds ratios with $95 \% \mathrm{Cl}$ ) of legume intake and selected factors on the risk of diabetes among men

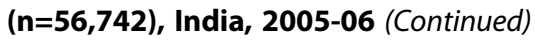

\begin{tabular}{|c|c|c|c|c|c|}
\hline Geographic regions & & & & & $<0.0001$ \\
\hline North $^{R}$ & & & & 1.00[Reference] & \\
\hline Northeast & & & & $2.02[1.14-3.58]$ & \\
\hline Central & & & & $1.44[0.98-2.13]$ & \\
\hline East & & & & $3.06[2.09-4.48]$ & \\
\hline West & & & & $1.49[1.01-2.20]$ & \\
\hline South & & & & $3.27[2.27-4.71]$ & \\
\hline Number of cases & 56,729 & 56,665 & 52,746 & 52,693 & \\
\hline
\end{tabular}

For variable definition see Table 1 i $^{\mathrm{R}}$ Reference category; Model 1 unadjusted; Model 2 adjusted for consumption of other food items and background factors; Model 3 adjusted for BMI and other lifestyle indicators and background factors; Model 4 adjusted for all.

p-Likelihood ratio test for no difference between the three groups for age and standard of living index ignoring the correlated data. As the urban group was expected to have the highest and the rural group the lowest levels of risk factors and disease,

trend tests were carried out scoring the groups 1 to 3 and using likelihood ratio tests.

prevalence of diabetes among them. The overall prevalence of diabetes is higher among men $(1.3 \%)$ than among women $(1.1 \%)$. Daily or weekly legume consumption was associated with a lower prevalence of diabetes among men $(1.5 \%)$ and women $(1.0 \%)$ than observed in people never eating legumes (men $2.6 \%$ and women $2.3 \%$ ). Diabetes was more common among both men and women who consumed milk or curd, eggs, fish, chicken or meat daily or weekly, never consumed fruits, who were either overweight or obese, who watched television almost every day, and in those who were the oldest age group, lived in urban areas and in wealthier households (all $\mathrm{p}<0.0001)$. Strong associations between age and diabetes prevalence were observed. Diabetes prevalence increased according to the wealth of the household and was almost double in urban women and men compared with their rural counterparts. Those living in the southern (men 2.0\% and women 1.6\%) and eastern regions (men 1.8\% and women 1.3\%) of India had the highest prevalence of diabetes and those in the central region had the lowest prevalence (men and women both $0.6 \%)$. No differences in prevalence were seen for green leafy vegetable consumption or smoking tobacco or alcohol consumption. No clear pattern of prevalence by education was also seen.

\section{Association between legume consumption, modifiable risk factors and control variables and diabetes risk among men}

Unadjusted odds (Model 1, Table 2) of suffering from diabetes are more than 40 percent lower (OR: 0.57; 95\% CI: 0.32-0.99) among men who consume legumes daily, 61 percent lower (OR: 0.39; 95\% CI: 0.22-0.69) among those who consume legumes at least weekly, 58 percent lower (OR: 0.42; 95\% CI: 0.23-0.79) among those who consume them occasionally, as compared to those who never consumed legumes. Controlling for consumption of other food items (in Model 2) retains this inverse association but $\mathrm{p}$ value becomes non-significant. The effect of legume intake remains virtually unchanged when BMI and other lifestyle factors are additionally controlled in Model 3. When the socio-economic control variables and other covariates are included (Model 4), the effect of legume intake is not significant although the direction of association remains the same.

\section{Association between legume consumption, modifiable risk factors and control variables and diabetes risk among women}

Unadjusted odds (Model 1, Table 3) of suffering from diabetes are 57\% (OR: 0.43; 95\% CI: 0.27-0.67), 59\% (OR: 0.41; 95\% CI: $0.26-0.65$ ) and 43\% (OR: 0.57; 95\% CI: 0.360.92) lower among those who consumed legumes daily, weekly or at least occasionally, respectively, compared to those who never consumed legumes. Controlling for consumption of other food items (in Model 2) maintains this significant inverse relationship. The effect of legumes intake remains virtually unchanged (OR ranges from 0.46 to 0.71 ) when BMI and other lifestyle factors are additionally controlled in Model 3 . Even when the socio-economic control variables are included in Model 4, effect of daily (OR: 0.55; 95\% CI: 0.34-0.88) or weekly (OR: 0.56; 95\% CI: 0.35-0.90) legume consumption still has a reduced and statistically significant effect on the prevalence of diabetes among women.

\section{Discussion}

Legume consumption is nearly ubiquitous in Indian diets - more than $99 \%$ of the study population reported consuming some pulses or beans preparation either daily, weekly or occasionally. Overall, we found daily or weekly legumes intake were associated with a significantly reduced prevalence of diabetes among adult Indian women whereas non-significant inverse associations were observed in case of men. The association is robust after controlling for other risk factors such as consumption of other food items, BMI, 
Table 3 Effect (odds ratios with $95 \% \mathrm{Cl}$ ) of legumes intake and selected factors on the risk of diabetes among women (n=99,574), India, 2005-2007

\begin{tabular}{|c|c|c|c|c|}
\hline Predictors and confounders & $\begin{array}{c}\text { Model } 1 \text { OR } \\
{[95 \% \mathrm{Cl}]}\end{array}$ & $\begin{array}{c}\text { Model } 2 \text { OR } \\
{[95 \% \mathrm{Cl}]}\end{array}$ & $\begin{array}{c}\text { Model } 3 \text { OR } \\
{[95 \% \mathrm{Cl}]}\end{array}$ & $\begin{array}{c}\text { Model } 4 \text { OR } \\
{[95 \% \mathrm{Cl}]}\end{array}$ \\
\hline \multicolumn{5}{|l|}{ Legumes intake } \\
\hline Daily & $0.43[0.27-0.67]$ & $0.53[0.33-0.85]$ & $0.46[0.29-0.74]$ & $0.55[0.34-0.88]$ \\
\hline Weekly & $0.41[0.26-0.65]$ & $0.56[0.35-0.89]$ & $0.51[0.32-0.82]$ & $0.56[0.35-0.90]$ \\
\hline Occasionally & $0.57[0.36-0.92]$ & $0.71[0.44-1.16]$ & $0.71[0.43-1.15]$ & $0.74[0.45-1.20]$ \\
\hline Never $^{R}$ & 1.00[Reference] & 1.00[Reference] & 1.00[Reference] & 1.00[Reference] \\
\hline
\end{tabular}

Consumption of other food items

Milk or curd

1.09[0.87-1.37]

Daily

Weekly

Occasionally

Never $^{R}$

Green leafy vegetables

Daily

Weekly

Never/occasionally ${ }^{\mathrm{R}}$

Fruits

Daily

Weekly

Occasionally

Never $^{\mathrm{R}}$

Eggs

Daily

Weekly

Occasionally

Never $^{R}$

Fish

Daily
Weekly
Occasionally
Never $^{R}$
Chicken or meat
Daily
Weekly
Occasionally $^{\text {Never }}$

Body mass index and lifestyle factors

Body mass index $\left(\mathrm{kg} / \mathrm{m}^{2}\right)$

$\leq 18.5$ (Underweight)

18.5-22.9 (Normal) ${ }^{\mathrm{R}}$

23.0-24.9 (Overweight)

$\geq 25.0$ (Obese)

Current Tobacco smoking
$0.99[0.76-1.29]$

$1.02[0.81-1.27]$

$1.00[$ Reference]

$0.90[0.70-1.15]$

$0.99[0.77-1.28]$

$1.00[$ Reference]

$0.45[0.32-0.62]$

$0.37[0.27-0.50]$

$0.45[0.34-0.60]$

1.00[Reference]

$1.06[0.75-1.50]$

0.97[0.76-1.23]

0.93[0.72-1.16]

1.00[Reference]

1.25[0.91-1.70]

$1.12[0.84-1.48]$

0.83[0.63-1.08]

1.18[0.64-2.17]

$1.02[0.76-1.38]$

1.12[0.84-1.47]

1.00[Reference]
1.00[Reference]
0.005

1.05[0.83-1.32]

1.00[0.77-1.30]

$1.01[0.81-1.27]$

1.00[Reference]

0.88[0.69-1.14]

1.00[0.77-1.29]

1.00[Reference]

$0.44[0.32-0.61]$

$0.36[0.27-0.49]$

0.46[0.34-0.61]

1.00[Reference]

0.106

0.99[0.69-1.41]

0.97[0.76-1.25]

0.96[0.75-1.22]

1.00[Reference]

1.15[0.84-1.58]

1.05[0.79-1.40]

0.81[0.61-1.07]

1.00[Reference]

0.267

1.05[0.55-1.98]

1.02[0.77-1.38]

$1.11[0.84-1.48]$

1.00[Reference]

$<0.0001$

$\begin{array}{ll}0.78[0.63-0.97] & 0.79[0.63-0.98] \\ 1.00[\text { Reference }] & 1.00[\text { Reference }] \\ 1.69[1.39-2.07] & 1.67[1.37-2.04] \\ 2.52[2.13-2.95] & 2.50[2.13-2.94]\end{array}$


Table 3 Effect (odds ratios with $95 \% \mathrm{Cl}$ ) of legumes intake and selected factors on the risk of diabetes among women (n=99,574), India, 2005-2007 (Continued)

$\mathrm{No}^{\mathrm{R}}$
Yes
Alcohol consumption
Never $^{\mathrm{R}}$
Occasionally
Once a week
Almost everyday
Frequency of watching TV
Not at all
Less than once a week
At least once a week
Almost everyday

\section{Background factors}

Age

$$
\begin{aligned}
& 20-29^{R} \\
& 30-39 \\
& 40-49
\end{aligned}
$$

$\begin{array}{ll}1.00 \text { [Reference] } & 1.00[\text { Reference] } \\ 1.26[0.79-2.02] & 1.24[0.77-2.00]\end{array}$

Education

Illiterate $^{\mathrm{R}}$

Literate, < middle school

Middle school completed

High school complete and above

Religion

Hindu ${ }^{R}$

Muslim

Christian

Sikhs

Others

Caste/tribe

Scheduled caste ${ }^{R}$

Scheduled tribes

Other backward class

Others

Missing caste

Wealth index

Lowest $^{R}$

Second

Middle

Fourth

Highest

Place of residence

Urban

Rural $^{\text {R }}$
$<0.0001$

$<0.0001$

1.00[Reference]

3.29[2.64-4.09]

7.82[6.32-9.68]

1.00[Reference]

1.38[1.14-1.68]

1.49[1.24-1.79]

$0.99[0.73-1.34]$

1.00[Reference]

1.23[1.01-1.51]

$1.58[1.17-2.14]$

0.97[0.61-1.56]

1.12[0.66-1.92]

1.00[Reference]

0.56[0.37-0.86]

$0.87[0.71-1.05]$

0.97[0.79-1.18]

0.85[0.58-1.25]

$<0.0001$

1.00[Reference]

1.64[1.22-2.21]

$1.41[1.03-1.92]$

1.87[1.36-2.57]

$1.93[1.35-2.74]$

$<0.0001$

1.45[1.25-1.69]

1.00[Reference] 

characteristics; Model 3 adjusted for BMI and other lifestyle indicators and background characteristics; Model 4 adjusted for all.

tobacco smoking, alcohol drinking, and a range of socioeconomic and demographic characteristics.

Our study is the first cross sectional, population-based study to look at frequency of legume consumption and prevalence of diabetes in India, and adds to the limited data on the associations between legume intake and diabetes prevalence in developing countries. The results of this study are in line with other epidemiologic studies focusing on legumes specifically, which show inverse associations between legumes and diabetes in some of the studies $[12,13,17]$, but not in all $[14-16,18]$. However, in studies conducted in Asian countries, the inverse associations are primarily due to soy intake $[2,17,27]$. Evaluations of dietary patterns have identified legumes as an important component of both the 'prudent diet' [28] and 'Mediterranean diet' [29], which have been associated with a lower risk of diabetes in some [30,31] but not all large cohort studies [28].

It has been suggested that diets high in legumes are beneficial in preventing and managing diabetes, as they are whole grain foods with high insoluble fibre and low glycemic index [32]. The protective effect of legumes on diabetes may be due to multiple biological reasons, including increased fiber content in the diet [33], a reduction in the glycemic index of mixed meals [34], or both. In addition, legumes contain polyphenols, such as isoflavones and lignans, which have an antioxidant effect and may be responsible for the protective role of legumes against the development of diabetes [2]. Though there are several plausible mechanisms by which legumes could reduce diabetes risk and improve glycemic control, some uncertainties still remain [35]. It is possible that this protection is afforded by the intact structure of the pulses slowing digestion and partially restricting absorption of the glycemic carbohydrate [35].

The prevalence of self-reported diabetes in this large nationally representative survey was comparatively low (about 1\%) reflecting the young age of this population and the use of self-reports rather than biochemical assessments. Estimates from a recent study of ruralurban migrants showed an age-adjusted prevalence of diabetes (diagnosed using both self-reports and fasting blood glucose in relatively affluent populations) of 1015 percent in urban people and 5-6 percent in rural people of similar age to those recruited in NFHS-3 [36]. In most urban areas of India the health system is sufficiently developed to diagnose symptomatic diabetes, but at younger ages ( $<30$ years) diabetes may not be symptomatic, and thus NFHS-3 prevalence estimates are undoubtedly conservative, particularly for rural India where diagnosis may be much less likely to occur. However, this ascertainment bias is unlikely to have been differential with respect to legume consumption.

It is necessary to acknowledge that our study has several limitations. Misclassification of dietary information, although unavoidable, would most likely not allow for true associations. Again, there is a possibility that the information derived from the NFHS-3 questionnaire, while critical to measure true dietary intake, may not meet the standards of validity [37] despite the fact that NFHS-3 is a part of the Demographic and Health Surveys (www.measuredhs.com) conducted in more than 90 countries, and a similar questionnaire seems to get a fairly valid overall picture of frequency of dietary intake in a population. Another limitation of our study is reliance on self-reports of diabetes. This has resulted in a marked underestimation of prevalence, and its focus on people $<60$ years in whom diabetes is less common [25]. Self-reported data, especially in rural areas, can be flawed owing to several factors such as lack of awareness, low educational status, limited access to health services and hesitation to disclose diagnosed diseases [25]. Moreover, we were also unable to distinguish between Type 1 and 2 diabetes diagnoses. Under and over reporting could lead to a biased estimation of the association between dietary factors and diabetes. Although we adjusted for several confounding variables, we cannot exclude the possibility of residual confounding. However, if this was the case, 
similar effects would be expected for other dietary components that are also related to greater affluence, which were not seen.

In these analyses, the cross-sectional design precludes causal inferences and we were limited to the questions used to elicit lifestyle and dietary information. Given the high proportion of undiagnosed diabetes in developing countries (www.worlddiabetesfoundation.org) where less than half of people with diabetes are diagnosed, there is a possibility that the exposure was associated with the likelihood of testing for diabetes, which may result in detection bias.

Importantly, the entire study was with known diabetic subjects who might have altered their diet and hence increased or decreased legume consumption due to dietary advice based on diabetes control and on the complications of diabetes like nephropathy. General dietary advice given to diabetic subjects is to include more whole grains and legumes, as evident in the results shown in Table 1, where more than 90 percent of the self-reported diabetics did report 'daily' or 'weekly' consumption of legumes. Other foods reported also reveal this fact - eggs and fruits 'daily' reported by fewer diabetic subjects whereas green leafy vegetables 'daily' reported by a larger number of diabetics - all suggest that the dietary choices of selfreported diabetic subjects might have been modified to manage diabetes. Despite these shortcomings, rigorous precautions were taken in the NFHS to obtain reliable self-reported data. The survey used the local terminology and commonly understood term of the disease, rigorously trained interviewers and supervisors and instituted standard quality checks.

\section{Conclusions}

In this large, cross sectional, population-based study of the adult Indian population, daily and weekly intake of legumes was associated with a reduced diabetes prevalence among women, whereas a non significant inverse association was found in men. These results add to the evidence that shows the beneficial effect of consuming legumes in countering the development of diabetes. However, the extent to which legumes contribute to the beneficial effect in terms of prevention and management of diabetes remain to be quantified. These findings need further corroboration by longitudinal and clinical studies but may well have public health significance in the Indian population. More epidemiological research with better measures of legumes intake and clinical measures of diabetes are needed to validate the findings in a developing country.

\section{Competing interest}

Both authors declare that they have no competing interests.

\section{Authors' contributions}

SA conceived the article. SA conducted and SE supervised the statistical analysis. SA wrote the paper and SE revised it for important intellectual content. All authors read and approved the final manuscript.

\section{Acknowledgements}

An earlier version of the paper was accepted for poster presentation at the International Workshop, Health, Morbidity and Mortality: the State of the Art, Vienna, Austria, September 1-3, 2011. SA is supported by a Wellcome Trust Strategic Award Grant No Z/041825. The support of the International Institute for Population Sciences (www.iipsindia.org) and Macro International (www.measuredhs.com) for providing access to the 2005-06 Indian National Family Health Survey data is gratefully acknowledged. We are also grateful to the two reviewers for their valuable comments and suggestion.

\section{Author details}

${ }^{1}$ South Asia Network for Chronic Disease, Public Health Foundation of India, C1/52, First floor, Safdurjung Development Area, New Delhi, India. ${ }^{2}$ London School of Hygiene and Tropical Medicine, London, UK.

Received: 8 August 2012 Accepted: 1 August 2013

Published: 2 August 2013

\section{References}

1. Zimmet P: Globalization, coca-colonization and the chronic disease epidemic: can the Doomsday scenario be averted? J Intern Med 2000, 247(3):301-310.

2. Villegas R, Gao YT, Yang G, Li HL, Elasy TA, Zheng W, Shu XO: Legume and soy food intake and the incidence of type 2 diabetes in the Shanghai Women's health study. Am J Clin Nutr 2008, 87:162-167.

3. Mann Jl, De Leeuw I, Hermansen K, Karamanos B, Karlstrom B, Katsilambros N, Riccardi G, Rivellese AA, Rizkalla S, et al: Evidence-based nutritional approaches to the treatment and prevention of diabetes mellitus. Nutr Metab Cardiovasc Dis 2004, 14:373-394.

4. CDACPGE: Canadian Diabetes Association 2008 clinical practice guidelines for the prevention and management of diabetes in Canada. Can J Diabetes 2008, 32:S1-S201.

5. Bantle JP, Wylie-Rosett J, Albright AL, Apovian CM, Clark NG, Franz MJ, Hoogwerf BJ, Lichtenstein AH, Mayer-Davis E, et al: Nutrition recommendations and interventions for diabetes: a position statement of the American Diabetes Association. Diabetes Care 2008, 31(Suppl 1):S61-S78.

6. Tiwari RR, Deb PK, Debbarma A, Chaudhuri R, Chakraborti A, Lepcha M, Chakraborti G: Risk factor analysis in self-reported diabetes in a rural Kerala population. Int J Diabetes Dev Ctries 2008, 28:91-94.

7. Vijayakumar G, Arun R, Kutty VR: High prevalence of type 2 diabetes mellitus and other metabolic disorders in rural Central Kerala. J Assoc Physicians India 2009, 57:563-567.

8. Misra A, Pandey RM, Devi JR, Sharma R, Vikram NK, Khanna N: High prevalence of diabetes, obesity and dyslipidaemia in urban slum population in northern India. Int J Obes Relat Metab Disord 2001, 25:1722-1729.

9. Ramachandran A, Snehalatha C, Vijay V: Low risk threshold for acquired diabetogenic factors in Asian Indians. Diabetes Res Clin Pract 2004, 65:189-195.

10. Mohan V, Deepa M, Deepa R, Shanthirani CS, Faroog S, Ganesan A, Datta M: Secular trends in the prevalence of diabetes and impaired glucose tolerance in urban South India-the Chennai urban rural epidemiology study (CURES-17). Diabetologia 2006, 49:1175-1178.

11. Messina MJ: Legumes and soybeans: overview of their nutritional profiles and health effects. Am J Clin Nutr 1999, 70(suppl):439S-450S.

12. Feskens $\mathrm{EJ}$, Bowles $\mathrm{CH}$, Kromhout $\mathrm{D}$ : Carbohydrate intake and body mass index in relation to the risk of glucose intolerance in an elderly population. Am J Clin Nutr 1991, 54:136-140.

13. Feskens EJ, Virtanen SM, Rasanen L, Tuomilehto J, Stengard J, Pekkanen J, Nissinen A, Kromhout D: Dietary factors determining diabetes and impaired glucose tolerance. A 20-year follow-up of the Finnish and Dutch cohorts of the seven countries study. Diabetes Care 1995, 18:1104-1112.

14. Meyer KA, Kushi LH, Jacobs DR Jr, Slavin J, Sellers TA, Folsom AR Carbohydrates, dietary fiber, and incident type 2 diabetes in older women. Am J Clin Nutr 2000, 71:921-930.

15. Heidemann C, Hoffmann K, Spranger J, Klipstein-Grobusch K, Mohlig M, Pfeiffer AF, Boeing $\mathrm{H}$ : A dietary pattern protective against type 2 diabetes in the European prospective investigation into cancer and nutrition (EPIC)-potsdam study cohort. Diabetologia 2005, 8:1126-1134.

16. Nanri A, Mizoue T, Takahashi Y, Kirii K, Inoue M, Noda M, Tsugane S: Soy product and isoflavone intakes are associated with a lower risk of type 2 diabetes in overweight Japanese women. J Nutr 2010, 140:580-586. 

Soy intake and risk of type 2 diabetes mellitus in Chinese Singaporeans: soy intake and risk of type 2 diabetes. Eur J Nutr 2012, 51(8):1033-40.

18. Morimoto Y, Steinbrecher A, Kolonel LN, Maskarinec G: Soy consumption is not protective against diabetes in Hawaii: the multiethnic cohort. Eur $J$ Clin Nutr 2011, 65:279-282.

19. International Institute for Population Sciences \& Macro International: National Family Health Survey (NFHS-3), 2005-06: India: Vol. I. Mumbai: IIPS; 2007.

20. Indian Consensus Group: Indian consensus for prevention of hypertension and coronary heart disease. A joint scientific statement of Indian society of hypertension and international college of nutrition. J Nutr Environ Med 1996, 6:309-318.

21. Minh HV, Ng N, Juvekar S, Razzaque A, Ashraf A, Hadi A, Soonthornthada K Bich $T H$, Kanungsukkasem U, Byass P: Self-reported prevalence of chronic diseases and their relation to selected sociodemographic variables: a study in INDEPTH Asian sites. Prev Chronic Dis 2008, 5(3):5-9.

22. Rao CR, Kamath VG, Shetty A, Kamath A: A study on the prevalence of type 2 diabetes in coastal Karnataka. Int J Diabetes Dev Ctries 2010, 30(2):80-85.

23. Mohan V, Mathur P, Deepa R, Deepa M, Shukla DK, Menon GR, Anand K, Desai NG, Joshi PP, Mahanta J, Thankappan KR, Shah B: Urban rural differences in prevalence of self-reported diabetes in India-the WHOICMR Indian NCD risk factor surveillance. Diabetes Res Clin Pract 2008, 80(1):159-168

24. Daniel CR, Prabhakaran D, Kapur K, Graubard BI, Devasenapathy N, Ramakrishnan L, George PS, Shetty H, Ferrucci LM, Yurgalevitch S, Chatterjee N, Reddy KS, Rastogi T, Gupta PC, Mathew A, Sinha R: A cross-sectional investigation of regional patterns of diet and cardio-metabolic risk in India. Nutr J 2011, 10(12):1-13.

25. Agrawal S, Ebrahim S: Prevalence and risk factors for self-reported diabetes among adult men and women in India: findings from a national cross-sectional survey. Public Health Nutr 2011, 15(6):1065-1077.

26. Griffiths PL, Bentley ME: The nutrition transition is underway in India. J Nutr 2001, 131(10):2692-2700.

27. Odegaard AO, Koh WP, Butler LM, Duval S, Gross MD, Yu MC, Yuan JM, Pereira MA: Dietary patterns and incident type 2 diabetes in Chinese men and women: the Singapore Chinese health study. Diabetes Care 2011, 34:880-885.

28. Fung TT, Schulze M, Manson JE, Willett WC, Hu FB: Dietary patterns, meat intake, and the risk of type 2 diabetes in women. Arch Intern Med 2004, 164:2235-2240.

29. Trichopoulos D, Lagiou P: Mediterranean diet and cardiovascular epidemiology. Eur J Epidemiol 2004, 19:7-8.

30. Martinez-Gonzalez MA, Fuente-Arrillaga De La C, Nunez-Cordoba JM, Basterra-Gortari FJ, Beunza JJ, Vazquez Z, Benito S, Tortosa A, Bes-Rastrollo M: Adherence to Mediterranean diet and risk of developing diabetes: prospective cohort study. BMJ 2008, 336:1348-1351.

31. Romaguera D, Guevara M, Norat T, et al: Mediterranean diet and type 2 diabetes risk in the European prospective investigation into cancer and nutrition (EPIC) study: the InterAct project. Diabetes Care 2011, 34:1913-1918.

32. Salas-Salvado J, Martinez-Gonzalez MA, Bullo M, Ros E: The role of diet in the prevention of type 2 diabetes. Nutr Metab Cardiovasc Dis 2011, 21(Suppl 2):B32-B48.

33. Hu FB, Van Dam RM, Liu S: Diet and risk of type II diabetes: the role of types of fat and carbohydrate. Diabetologia 2001, 44(7):805-817.

34. Jenkins DJ, Wolever TM, Buckley G, et al: Low-glycemic-index starchy foods in the diabetic diet. Am J Clin Nutr 1988, 48(2):248-254.

35. Venn BJ, Mann Jl: Cereal grains, legumes and diabetes. Eur I Clin Nutr 2004, 58(11):1443-1461.

36. Ebrahim S, Kinra S, Bowen L, Andersen E, Ben-Shlomo Y, Lyngdoh T, Ramakrishnan L, Ahuja RC, Joshi P, et al: The effect of rural-to-urban migration on obesity and diabetes in India: a cross-sectional study. PLoS Med 2011, 7:e1000268.

37. Pullum TW: An assessment of the quality of data on health and nutrition in the DHS surveys, 1993-2003. Methodological Reports No. 6. Calverton, Maryland, USA: Macro International Inc.; 2008.

\section{doi:10.1186/1471-2458-13-706}

Cite this article as: Agrawal and Ebrahim: Association between legume intake and self-reported diabetes among adult men and women in India. BMC Public Health 2013 13:706.

\section{Submit your next manuscript to BioMed Central and take full advantage of:}

- Convenient online submission

- Thorough peer review

- No space constraints or color figure charges

- Immediate publication on acceptance

- Inclusion in PubMed, CAS, Scopus and Google Scholar

- Research which is freely available for redistribution 